\title{
Polymorphisms in the pituitary growth hormone gene and its receptor associated with coronary artery disease in a predisposed cohort from India
}

\author{
ARINDAM MAITRA ${ }^{1 *}$, JAYASHREE SHANKER ${ }^{1 *}$, DEBABRATA DASH ${ }^{1}$, PRATHIMA R. SANNAPPA $^{1}$, \\ SHIBU JOHN ${ }^{2}$, PRATIBHA SIWACH ${ }^{1}$, VEENA S. RAO ${ }^{3}$, H. SRIDHARA ${ }^{2}$ and VIJAY V. KAKKAR ${ }^{1,4}$ \\ ${ }^{1}$ Mary and Garry Weston Functional Genomics Unit, ${ }^{2}$ Elizabeth and Emmanuel Kaye Bioinformatics and Statistics Unit, \\ ${ }^{3}$ Tata Proteomics and Coagulation Unit, Thrombosis Research Institute India, 258/A, Bommasandra Industrial Area, \\ Bangalore 560 099, India \\ ${ }^{4}$ Thrombosis Research Institute-London, Emmanuel Kaye Building, Manresa Road, Chelsea SW3 6LR, London, UK
}

\begin{abstract}
We investigated the promoter polymorphisms of the pituitary growth hormone gene $(G H 1)$ and exon 3 deletion polymorphism $(G H R d 3)$ in its receptor gene $(G H R)$ in 299 angiographically proven patients with coronary artery disease (CAD) and 231 asymptomatic controls enrolled in the ongoing Indian Atherosclerosis Research Study. Real time PCR based analysis of the GHR variant showed significant association of the GHRd3 deletion allele with CAD (OR 0.48, 95\% CI: 0.30-0.76, $P=$ 0.0014 ) and a dominant model of inheritance (Akaike information criterion $=482$ ). The deletion allele showed significant association with high plasma HDL-c levels $(P=0.001)$. Sequencing of the proximal promoter region of $G H 1$ revealed 12 novel polymorphisms and a TAGA haplotype constituted by the functional SNPs rs2005171, rs11568828, rs2005172 and rs6171, that showed significant association with CAD alone (adjusted OR of $3.31(95 \% \mathrm{CI}=1.33-8.29, P=0.011)$ and in CAD patients with diabetes $(P=0.019)$. Mean standardized height was associated with three of the four haplotype-tagging SNPs in the cohort $(P \leq 0.03)$. Eleven of the 12 polymorphic promoter SNPs contributed to $14.7 \%$ of variation in height in females in the whole dataset $(P=0.029)$. CAD patients with history of stroke exhibited marginally significantly lower mean height as compared to rest of the cohort $(P<0.006)$. In conclusion, genetic polymorphisms in the $G H R$ gene and its ligand, $G H 1$, may modulate the risk of CAD in the Asian Indian population.
\end{abstract}

[Maitra A., Shanker J., Dash D., Sannappa P. R., John S., Siwach P., Rao V. S., Sridhara H. and Kakkar V. V. 2010 Polymorphisms in the pituitary growth hormone gene and its receptor associated with coronary artery disease in a predisposed cohort from India. J. Genet. 89, 437-447]

\section{Introduction}

The growth hormone (GH)-insulin-like growth factor (IGF1) axis that influences postnatal growth encompasses a multitude of genes that regulate complex diseases including developmental disorders, ageing, cancer, cardiovascular diseases (CVD) and their comorbidities (Rodriguez et al. 2007). The pituitary growth hormone plays a critical role in postnatal development (Garcia-Aragon et al. 1992). The discovery of 'fetal programming' that relates to the influence of adverse fetal environment on development of metabolic and CVD

*For correspondence. E-mail: Jayashree Shanker, jayashreeshanker@ triindia.org.in; Arindam Maitra, arindam@triindia.org.in. during adult life (Barker 1995) has brought an intriguing twist to our understanding on the expansive role of the human GH. Recent studies suggest that GH deficiency can lead to the development of atherosclerosis by influencing vascular reactivity and by regulating cardiac growth and function (Cittadini et al. 1994; Climent et al. 2006). Administering recombinant growth hormone in children with $\mathrm{GH}$ deficiency (GHD) (Minczykowski et al. 2005) and in patients with chronic heart failure (Le Corvoisier et al. 2007) results in improved cardiovascular parameters and reverses early atherosclerotic changes in adult GH-deficient men (Pfeifer et al. 1999a). Short stature has been associated with elevated blood pressure (Langenberg et al. 2005) and increased risk of atherosclerosis (Reed et al. 1988). Studies suggest a pos-

Keywords. growth hormone; growth hormone receptor; coronary artery disease; height; Asian Indian. 
sible link between GH, stature and arterial function (Horan et al. 2006). An inverse relationship between adult height and risk of hypertension, and stroke has been reported (McCarron et al. 2000; Song et al. 2003), with involvement of the GH1-IGF1 growth axis (Bondanelli et al. 2006).

The proximal promoter region of $G H 1$ gene, which encodes the pituitary growth hormone, is highly polymorphic and contains at least 15 well-described single nucleotide polymorphisms (SNPs) (Horan et al. 2003). Over 40 different haplotypes have been identified, some of which are associated with altered reporter gene expression. By applying haplotype partitioning, 6SNPs were determined as major determinants of $\mathrm{GHl}$ gene expression (Horan et al. 2006). They also identified three haplotypes in the locus control region (LCR), located upstream of the $G H 1$ gene, that enhances the promoter activity up to nearly 2.8 -fold.

The downstream effect of $G H 1$ is initiated by the binding of circulating $G H 1$ molecules to its cellular receptor, encoded by the GHR gene, followed by STAT-1 mediated cell signalling that ultimately stimulates the GH-IGF axis. A copy number variation of exon 3 of $G H R$ has been shown to influence response to $\mathrm{GH}$ therapy in children with idiopathic short stature (Ko et al. 2009) and other developmental abnormalities (Jensen et al. 2007; Binder et al. 2008) with better hormonal response seen in patients carrying the exon 3 deletion allele. However, there have also been reports to the contrary (Blum et al. 2006; Carrascosa et al. 2008). Multiple reports have implied that the truncated gene product might be associated with enhanced cell signalling initiated by the $G H-G H R$ binding, which leads to differential stimulation of the GH-IGF axis. Considering the pleiotropic effect of pituitary GH on CVD risk, the objective of the present study was to explore the genetic variations of $G H 1$ promoter and $G H R$ genes in the context of a hitherto untested Asian Indian cohort with high predisposition to CAD and stroke.

\section{Materials and methods}

\section{Study population}

Participants selected from the ongoing Indian Atherosclerosis Research Study (IARS) were recruited from Bangalore and Mumbai, located in southern and western India, respectively. The inclusion criteria for the $299 \mathrm{CAD}$ patients were as follows: diagnosis by echocardiogram and/or coronary angiography, surgical treatment by percutaneous transluminal coronary angioplasty or bypass graft, age at onset $\leq 60$ and $\leq 65$ years for men and women, respectively, and presence of strong family history of CVD. A total of 231 healthy volunteers who were asymptomatic for CAD and did not have a family history of CVD were enrolled from the population and served as controls. ECG was performed for all controls and only those with normal ECG were included for the study. All participants were free from concomitant infections. Blood samples were collected from study participants by informed voluntary consent. The study was approved by the institu- tional ethics committee and was according to the guidelines of the Indian Council of Medical Research (ICMR) (Kumar 2006) and Helsinki Declaration for Medical Research on Human Subjects (World Medical Association declaration of Helsinki 1997). The study was estimated to have $92 \%$ power to detect 1.5 -fold change in risk allele frequency given $40 \%$ frequency of the risk allele and type 1 error probability of 0.05 .

\section{Anthropometric measurements and lipid assays}

Height and weight were measured while body mass index was calculated. Prevalence of diabetes and hypertension were ascertained based on self-report of physician's diagnosis and/or use of prescription medications. Plasma and serum were stored as aliquots at $-80^{\circ} \mathrm{C}$ and genomic DNA was isolated from blood pellets using the salting out procedure (Miller et al. 1988). Plasma total cholesterol (TC) and triglyceride (TG) were measured using reagents and standards from Randox laboratories (Crumlin, UK) while reagents from Bayer diagnostics (Newbury, UK), controls from Randox (Crumlin, UK) and standards from Dade Behring Ltd (Milten Keynes, UK) were used to assay for high-density lipoprotein-cholesterol (HDL-c). Low-density lipoprotein-cholesterol (LDL-c) was calculated by Friedwald's formula (Johnson et al. 1997) for samples with TG value less than $400 \mathrm{mg} / \mathrm{dL}$ (Friedewald et al. 1972). The inter-assay coefficient of variation (CV) for the commercial controls and normal serum pool ranged from $4.9 \%$ to $7.0 \%$ for TC, $6.1 \%$ to $7.7 \%$ for TG and $7.1 \%$ to $12.2 \%$ for HDL-c.

\section{Sequencing of the $\mathrm{GH} 1$ promoter region}

The 878 base pair (bp) region of the proximal promoter region of $\mathrm{GHI}$ gene was amplified from genomic DNA samples in 283 cases (214 men, 69 women) and 206 controls (135 men, 71 women) using oligonucleotide primers 271F (5' -GTGTCTCTGCTGCAAGTCCAA) and 1148R (5'-CATGGCGATACTCACATTCAGAA) and True Allele PCR Mix in 9700 PCR instrument (Applied Biosystems, Foster City, USA). PCR conditions: $95^{\circ} \mathrm{C}$ for $12 \mathrm{~min}, 35 \mathrm{cy}-$ cles of $95^{\circ} \mathrm{C}$ for $1 \mathrm{~min}, 60^{\circ} \mathrm{C}$ for $30 \mathrm{~s}, 72^{\circ} \mathrm{C}$ for $1 \mathrm{~min}$ and a final hold at $72^{\circ} \mathrm{C}$ for $10 \mathrm{~min}$. PCR products were purified by ExoSAPit digestion (Amersham Biosciences, Piscataway, USA), sequenced bidirectionally using PCR primers and Big Dye Terminator v 3.1 sequencing kit from ABI as per manufacturer's recommendations and analysed in 3130XL automated genetic analyzer (Applied Biosystems, Foster City, USA). Sequence data were compared with reference sequence downloaded from Ensembl Genome Browser release 44-April 2007 (Hubbard et al. 2007) and screened for sequence polymorphisms with SeqScape v 2.5 software (Hubbard et al. 2007).

\section{Copy number variation of GHRd3}

Detection of variation in copy number of exon 3 deletion of the $G H R$ gene $(G H R d 3)$ was performed by real time 
PCR in ABI 7500 Real Time PCR system (Applied Biosystems, Foster City, USA) based on previously described method (Horan et al. 2006). Briefly, the exon 3 genomic region was amplified using oligonucleotide primers, GHRX3F $\left(5^{\prime}\right.$ - TCTGTTTCAGCCACAGCAGCTA) and GHRX3R (5' - TGTCTTTAGGCCTGGATTAACACTT) using SYBR Green I PCR Master mix (Applied Biosystems, Foster City, USA). PCR conditions: $50^{\circ} \mathrm{C}$ for $2 \mathrm{~min}, 95^{\circ} \mathrm{C}$ for $10 \mathrm{~min}$ and 40 cycles of $95^{\circ} \mathrm{C}$ for $15 \mathrm{~s}, 60^{\circ} \mathrm{C}$ for $1 \mathrm{~min}$ followed by dissociation curve analysis to confirm the specificity of PCR amplification. Exon 10 of $G H R$ was simultaneously amplified as endogenous control with oligonucleotide primers $G H R X 10 F$ (5' - CCCAGGTGAGCGACATTACA) and GHRX10R (5' - CATCCCTGCCTTATTCTTTTGG). Calculation of copy number of GHRd3 allele was performed by relative quantitation approach using exon 10 as endogenous control and based on specific assay efficiencies (Pfaffl 2001). Individuals homozygous for full length $G H R$ and exon 3 deleted $G H R$ genes would have zero and two copies of GHRd3 allele respectively, while heterozygous individuals would have one copy of the deletion allele.

\section{Statistical analysis}

Deviation from Hardy-Weinberg proportions was assessed by $\chi^{2}$ test. Correspondence analysis was performed using Minitab v14 (Minitab, Pennsylvania, USA) (Greenacre 1984) to assess the contribution of $G H 1$ promoter SNPs to genetic variability in the dataset. Estimation of significant differences in the distribution of $G H 1$ promoter genotypes and GHRd3 deletion polymorphism between cases and con- trols, haplotype analysis and estimation of odds ratio (OR) was performed by logistic regression analysis with SNPStat online software tool and Haploview v 4.0 software (Barrett et al. 2005; Sole et al. 2006). The percentage of population attributable risk (PAR) was estimated by Winpepi (Abramson 2004). Routine statistical analysis was carried out with SPSS v 17 software (SPSS, Chicago, USA). All quantitative values are represented as mean \pm standard error (s.e.). Differences in group means for age, BMI, height, waist-hip ratio, systolic and diastolic blood pressure were assessed by 2-tailed Student $t$-test. Normality of plasma HDL-c levels was assessed by Kolmogorov-Smirnov test and Q-Q plots, and data were log-transformed for normalization. Analysis of variance was performed to assess the association of CAD and stroke with standardized height (height Z-score) and GHI promoter genotypes and GHRd3 allele copy number with plasma HDL-c levels with and without adjustment for significant clinical covariates. Linear regression analysis was performed to assess the significant promoter SNPs that contributed to standardized height. A nominal $P$ value of 0.05 or less was considered as statistically significant.

\section{Results}

\section{Clinical characteristics}

Detailed clinical characteristics of study cohort are provided in table 1. A total of 530 subjects comprising of 299 CAD patients and 231 control subjects were enrolled in the study. The mean age at onset of CAD was $45.58 \pm 0.58$ years and $51.59 \pm 0.92$ years in men and women, respectively. Over 42

Table 1. Clinical characteristics of the study participants.

\begin{tabular}{lccr}
\hline Description & $\begin{array}{c}\text { Control } \\
(n=231)\end{array}$ & $\begin{array}{c}\text { Case } \\
(n=299)\end{array}$ & $P$ value \\
\hline Age & $47.4 \pm 0.48$ & $50.68 \pm 0.50$ & 0.001 \\
Gender (M/F) & $156 / 75$ & $227 / 72$ & 0.032 \\
BMI $\left(\mathrm{kg} / \mathrm{m}^{2}\right)$ & $25.23 \pm 0.28$ & $26.18 \pm 0.24$ & 0.011 \\
Height $(\mathrm{cm})$ & $162.01 \pm 0.58$ & $163.25 \pm 0.48$ & 0.098 \\
Weight(kg) & $66.17 \pm 0.85$ & $69.8 \pm 0.66$ & 0.001 \\
Waist/Hip Ratio & $0.92 \pm 0.01$ & $0.95 \pm 0.003$ & $<0.0001$ \\
Systolic Blood Pressure (mm Hg) & $121.66 \pm 1.17$ & $125.65 \pm 0.99$ & 0.009 \\
Diastolic Blood Pressure (mm Hg) & $80.80 \pm 0.65$ & $81.38 \pm 0.50$ & 0.476 \\
Hypertension (\%) & $22(9.6)$ & $175(58.5)$ & $<0.0001$ \\
Diabetes (\%) & $11(4.8)$ & $132(44.1)$ & $<0.0001$ \\
Smoking (ever) & $59(25.8)$ & $124(41.6)$ & $<0.0001$ \\
Statin $(\%)$ & - & $202(71.1)$ & - \\
Total Cholesterol (mg/dL) & $184.8 \pm 2.39$ & $156.08 \pm 2.53$ & $<0.0001$ \\
Triglycerides (mg/dL) & $167.7 \pm 7.98$ & $163.33 \pm 4.4$ & 0.613 \\
HDL Cholesterol (mg/dL) & $45.86 \pm 0.76$ & $37.34 \pm 0.50$ & $<0.0001$ \\
LDL Cholesterol (mg/dL) & $107.52 \pm 2.06$ & $85.12 \pm 1.93$ & $<0.0001$ \\
\hline
\end{tabular}

Data are shown as mean \pm SEM. Differences in mean values for continuous traits (age, BMI, height, weight WHR, systolic blood pressure, diastolic blood pressure, all lipids) were tested by student $t$-test; Differences in frequency distribution for discrete variables (gender, hypertension, diabetes, smoking) were tested by chi square test. HDL cholesterol, high density lipoprotein cholesterol; LDL cholesterol, low density lipoprotein cholesterol; SEM, standard error of mean. 
men and 8 women had a history of stroke, 122 men and 53 women had hypertension, while 92 men and 40 women had diabetes, among the cases. Mean values of BMI, waist-hip ratio and systolic blood pressure were found to be significantly higher in cases as compared to the controls $(P<0.01)$.

\section{Analysis of GH1 promoter polymorphisms}

The 878-bp region of the $G H 1$ gene promoter that was sequenced in the present study harboured 16 single nucleotide polymorphisms (SNPs) which have been previously reported in the dbSNP. Table 2 a describes the allele frequency of the $16 \mathrm{dbSNP}$ SNPs while table $2 \mathrm{~b}$ provides details on frequency of the homozygous $(1,1$ and 2,2) as well as heterozygous genotypes for cases and controls (table 2). In addition, we also identified 12 novel sequence variants that have been subsequently submitted to the dbSNP (see table 1 in electronic supplementary material at http://www.ias.ac.in/jgenet).

Four of the $16 \mathrm{dbSNP}$ variants (rs2005170, rs7219235, rs2727338, rs11568827) were not polymorphic in our cohort, or showed a very low minor allele frequency $(1 \%)$ and therefore excluded from further analysis. Of the 12 polymorphic variants in the dbSNP, four SNPs: rs2005171, rs11568828, rs2005172 and rs6171 constituted the most informative markers with respect to our cohort. A schematic diagram of the 12 polymorphic SNPs spanning the proximal promoter region of $G H 1$ has been shown in figure 1 with the arrow below denoting the negative stand along with the nucleotide positions at 5' (at SNP rs2011732) and 3' (at SNP position rs2001345) regions.
The linkage disequilibrium (LD) structure for the 12 polymorphic SNPs have been shown in figure 1 of electronic supplementary material. Using correspondence analysis it has been shown that SNPs rs1811081 (ID \#2), rs2011732 (ID \#3), rs2005171 (ID \#4), rs2005172 (ID \#8) and rs6171 (ID \#10) included in the first two components, contributed to $89 \%$ of the genetic variability in our cohort (see figure 2; table 2 a,b in electronic supplementary material). The four most informative SNPs constituted a promoter haplotype, TAGA, which was significantly associated with CAD in the overall data analyses (OR 2.84, 95\% CI: 1.04-7.77, $P=0.043$ ) (table 3 ). This association remained significant after adjustment for age, gender, diabetes and hypertension $(\mathrm{OR}=3.31,95 \%$ CI: $1.338 .29, P=0.011)$. Subsequent analysis of CAD cases with diabetes $(n=123)$ against nondiabetic, nonCAD controls $(n=198)$ showed an OR of 3.52 (95\% CI 1.24-10.01, $P=0.019)$, while similar analysis on hypertensive CAD patients $(n=166)$ versus nonhypertensive, nonCAD controls $(n=192)$ was not statistically significant (OR of 2.79; 95\% CI 0.99 7.88, $P=0.054$ ) (table 3).

\section{Analysis of GHRd3 variant}

There was a significant difference in the distribution of copy number of exon 3 deletion allele, GHRd3, between CAD cases and controls $(P<0.0001)$ with relatively lower frequency of the two copy numbers among cases as compared to the controls (table 4). Assessment of different genetic models suggested a dominant inheritance model $(P<0.0014)$

Table 2a. Allele frequency of the $G H 1$ gene promotor SNPs in the study cohort.

\begin{tabular}{llcccc}
\hline & dbSNP & $\begin{array}{c}\text { Ancestral } \\
\text { allele } \\
\text { SNP }\end{array}$ & $\begin{array}{c}\text { Polymorphism } \\
\text { in the present } \\
\text { cohort }\end{array}$ & $\begin{array}{c}\text { Frequency } \\
\text { of allele }\end{array}$ & $\begin{array}{c}\text { Frequency } \\
\text { of allele }\end{array}$ \\
\hline rs2005170 & $\mathrm{A}>\mathrm{G}$ & $\mathrm{A}$ & $\mathrm{G}>\mathrm{A}$ & 1.0 & 2 \\
rs1811081 & $\mathrm{G}>\mathrm{T}$ & $\mathrm{G}^{*}$ & $\mathrm{G}>\mathrm{T}$ & 0.88 & 0.12 \\
rs2011732 & $\mathrm{G}>\mathrm{T}$ & $\mathrm{G}$ & $\mathrm{G}>\mathrm{T}$ & 0.88 & 0.12 \\
rs2005171 & $\mathrm{A}>\mathrm{G}>\mathrm{T}$ & $\mathrm{G}^{*}$ & $\mathrm{G}>\mathrm{T}$ & 0.75 & 0.25 \\
rs7219235 & $\mathrm{A}>\mathrm{G}$ & $\mathrm{G}$ & $\mathrm{G}$ & 1.0 & 0 \\
rs2727338 & $\mathrm{A}>\mathrm{G}$ & $\mathrm{A}$ & $\mathrm{T}>\mathrm{C}$ & 1.0 & 0 \\
rs11568828 & $\mathrm{C}>\mathrm{T}$ & $\mathrm{T}$ & $\mathrm{A}>\mathrm{G}$ & 0.96 & 0.04 \\
rs2005172 & $\mathrm{G}>\mathrm{T}$ & $\mathrm{G}$ & $\mathrm{T}>\mathrm{G}$ & 0.67 & 0.33 \\
rs11568827 & $->\mathrm{C}$ & $\mathrm{G}^{*}$ & $\mathrm{G}$ & 1.0 & 0 \\
rs6171 & $\mathrm{A}>\mathrm{G}$ & $\mathrm{A}$ & $\mathrm{A}>\mathrm{G}$ & 0.75 & 0.25 \\
rs695 & $\mathrm{A}>\mathrm{C}>\mathrm{T}$ & $\mathrm{A}^{*}$ & $\mathrm{~A}>\mathrm{T}$ & 0.97 & 0.03 \\
rs6175 & $\mathrm{C}>\mathrm{G}$ & $\mathrm{G}$ & $\mathrm{G}>\mathrm{C}$ & 1.0 & 0 \\
rs9282699 & $\mathrm{A}>\mathrm{G}$ & $\mathrm{A}$ & $\mathrm{A}>\mathrm{G}$ & 0.99 & 0.01 \\
rs6172 & $\mathrm{A}>\mathrm{C}$ & $\mathrm{A}$ & $\mathrm{A}>\mathrm{C}$ & 0.99 & 0.01 \\
rs6173 & $\mathrm{A}>\mathrm{C}>\mathrm{G}$ & $\mathrm{T}^{*}$ & $\mathrm{~T}>\mathrm{G}$ & 0.99 & 0.01 \\
rs2001345 & $\mathrm{C}>\mathrm{T}$ & $\mathrm{A}^{*}$ & $\mathrm{~A}>\mathrm{G}$ & 1.0 & 0 \\
\hline
\end{tabular}

1 denotes the ancestral allele and 2 denotes the mutant allele based on NCBI SNP database. *Where information on ancestral allele is not available in the NCBI SNP database, we have considered the more frequent allele in our cohort as the ancestral allele. ${ }^{\dagger}$ SNPs present on the negative strand. 
Table 2b. Genotype frequency of the $G H 1$ gene promotor SNPs in the study cohort.

\begin{tabular}{|c|c|c|c|c|c|c|c|c|c|c|}
\hline \multirow{2}{*}{\multicolumn{2}{|c|}{$\begin{array}{l}\mathrm{SNP}^{*} \\
\text { (chromosome }\end{array}$}} & \multicolumn{3}{|c|}{ Genotype $(1,1)$} & \multicolumn{3}{|c|}{ Genotype $(1,2)$} & \multicolumn{3}{|c|}{ Genotype $(2,2)$} \\
\hline & & \multicolumn{3}{|c|}{$n(\%)$} & \multicolumn{3}{|c|}{$n(\%)$} & \multicolumn{3}{|c|}{$n(\%)$} \\
\hline position) & Polymorphism & Case & Control & Total & Case & Control & Total & Case & Control & Total \\
\hline $\begin{array}{l}\text { rs2005170 } \\
(61996571)\end{array}$ & $\mathrm{G}>\mathrm{T}$ & & & 489 (1.0) & & & 0 & & & 0 \\
\hline $\begin{array}{l}\text { rs1811081 } \\
(61996506)\end{array}$ & $\mathbf{G}>\mathbf{T}$ & $219(0.78)$ & $159(0.78)$ & $378(0.78)$ & $59(0.21)$ & $40(0.2)$ & $99(0.20)$ & $4(0.01)$ & $5(0.02)$ & $9(0.02) 0$ \\
\hline $\begin{array}{l}\text { rs2011732 } \\
(61996499)\end{array}$ & $\mathbf{G}>\mathbf{T}$ & $221(0.78)$ & $159(0.77)$ & $380(0.78)$ & $58(0.2)$ & $43(0.21)$ & $101(0.21)$ & $4(0.01)$ & $4(0.02)$ & $8(0.01)$ \\
\hline $\begin{array}{l}\text { rs2005171 } \\
(61996476)\end{array}$ & $\mathbf{G}>\mathbf{T}$ & $164(0.58)$ & $121(0.59)$ & $285(0.58)$ & $90(0.32)$ & $71(0.34)$ & $161(0.33)$ & $29(0.1)$ & $14(0.07)$ & $43(0.09)$ \\
\hline $\begin{array}{l}\text { rs7219235 } \\
(61996425)\end{array}$ & $\mathrm{C}>\mathrm{T}$ & & & 489 (1.0) & & & 0 & & & 0 \\
\hline $\begin{array}{l}\text { rs2727338 } \\
(61996366)\end{array}$ & $\mathrm{T}>\mathrm{C}$ & & & $487(0.99)$ & & & $2(0.01)$ & & & 0 \\
\hline $\begin{array}{l}\text { rs11568828 } \\
(61996273)\end{array}$ & $\mathbf{A}>\mathbf{G}$ & $267(0.94)$ & $187(0.91)$ & $454(0.93)$ & $16(0.06)$ & $19(0.09)$ & $35(0.07)$ & & & $\mathbf{0}$ \\
\hline $\begin{array}{l}\text { rs2005172 } \\
(61996255)\end{array}$ & $\mathbf{T}>\mathbf{G}$ & $131(0.46)$ & $95(0.46)$ & $226(0.46)$ & $113(0.4)$ & $88(0.43)$ & $201(0.41)$ & $39(0.14)$ & $23(0.011)$ & $62(0.13) 0$ \\
\hline $\begin{array}{l}\text { rs11568827 } \\
(61996231)\end{array}$ & $\mathrm{G}>-$ & & & 489 (100.0) & & & 0 & & & \\
\hline $\begin{array}{l}\text { rs6171 } \\
(61996204)\end{array}$ & $\mathbf{A}>\mathbf{G}$ & $169(0.6)$ & $119(0.58)$ & $288(0.59)$ & $83(0.29)$ & $73(0.35)$ & $156(0.32)$ & $31(0.11)$ & 14 (.07) & $45(0.09)$ \\
\hline $\begin{array}{l}\text { rs695 } \\
(61996199)\end{array}$ & $\mathbf{A}>\mathbf{T}$ & $263(0.94)$ & $193(0.95)$ & $456(0.94)$ & $18(0.06)$ & $10(0.05)$ & $28(0.057)$ & & $1(0)$ & $1(0.003)$ \\
\hline $\begin{array}{l}\text { rs6175 } \\
(61996196)\end{array}$ & $\mathbf{G}>\mathbf{C}$ & $281(0.99)$ & $204(0.99)$ & 485 (0.99) & $2(0.01)$ & $2(0.01)$ & $4(0.01)$ & & & $\mathbf{0}$ \\
\hline $\begin{array}{l}\text { rs9282699 } \\
(61996183)\end{array}$ & $\mathbf{A}>\mathbf{G}$ & $275(0.97)$ & 203 (0.99) & $478(0.98)$ & $8(\mathbf{0 . 0 3})$ & $3(0.01)$ & $11(0.02)$ & & & $\mathbf{0}$ \\
\hline $\begin{array}{l}\text { rs6172 } \\
(61996174)\end{array}$ & $\mathbf{A}>\mathbf{T}$ & $275(0.97)$ & 203 (0.99) & $478(0.98)$ & $8(\mathbf{0 . 0 3})$ & $3(0.01)$ & $11(0.02)$ & & & $\mathbf{0}$ \\
\hline $\begin{array}{l}\text { rs6173 } \\
(61996140)\end{array}$ & $\mathbf{T}>\mathbf{G}$ & $275(0.97)$ & 204 (0.99) & $479(0.98)$ & $8(\mathbf{0 . 0 3})$ & $2(0.01)$ & $10(0.02)$ & & & $\mathbf{0}$ \\
\hline $\begin{array}{l}\text { rs2001345 } \\
(61996130)\end{array}$ & $\mathbf{A}>\mathbf{G}$ & 279 (0.99) & $206(1)$ & $485(0.99)$ & $4(0.01)$ & $\mathbf{0}$ & $4(0.01)$ & & & $\mathbf{0}$ \\
\hline
\end{tabular}

SNPs marked in bold indicate polymorphic variants having MAF $\geq 1 \%$

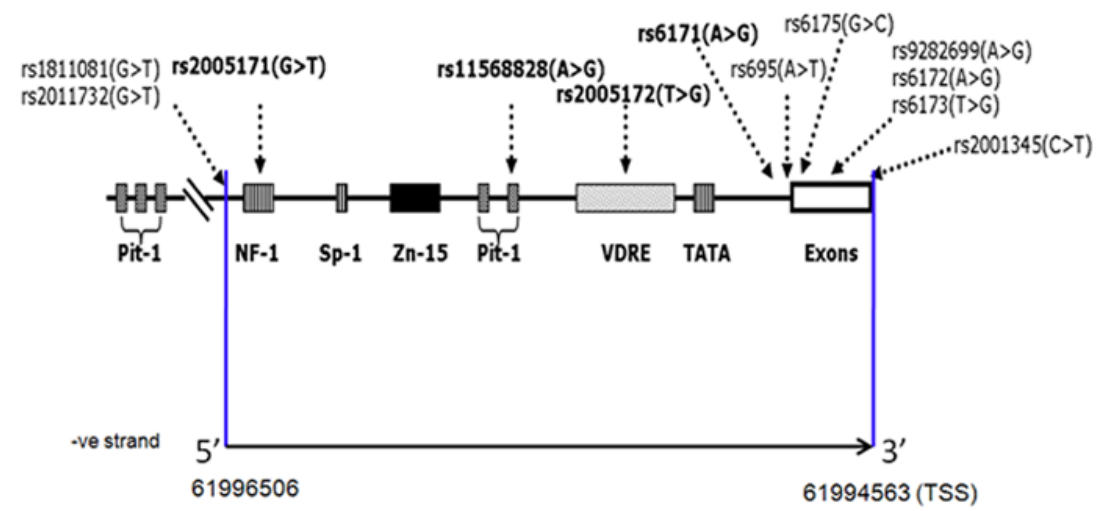

Figure 1. Schematic diagram showing 12 polymorphic SNPs spanning the proximal promoter region of GH1. SNPs marked in bold letters indicate the polymorphic variants that constitute the risk haplotype. Arrow below denotes negative stand with the nucleotide positions at 5' (at SNP rs2011732) and 3' (at SNP position rs2001345) regions. TSS, transcription start site. 
Arindam Maitra et al.

Table 3. Haplotype analysis of GH1 promoter SNPs rs2005171, rs11568828, rs2005172 and rs6171.

\begin{tabular}{|c|c|c|c|c|c|c|c|}
\hline \multirow[b]{2}{*}{ Group } & \multirow[b]{2}{*}{ Haplotype } & \multicolumn{2}{|c|}{ Frequency } & \multicolumn{2}{|l|}{ Unadjusted } & Adjusted & \multirow[b]{2}{*}{$P$ value } \\
\hline & & Case & Control & OR $(95 \% \mathrm{CI})$ & $P$ value & OR $(95 \% \mathrm{CI})$ & \\
\hline $\begin{array}{l}\text { CAD }(n=299) \text { vs } \\
\text { Contro }(n=231)\end{array}$ & TAGA & 0.037 & 0.0133 & $2.84(1.04-7.77)$ & 0.043 & $31.31(1.33-8.29)^{*}$ & 0.011 \\
\hline $\begin{array}{l}\text { CAD with Diabetes }(n=123) \text { vs } \\
\text { Control }(n=198)\end{array}$ & TAGA & 0.055 & 0.014 & $3.52(1.24-10.01)$ & 0.019 & $1.79(0.42-7.61)^{\#}$ & 0.43 \\
\hline $\begin{array}{l}\text { CAD with Hypertension } \\
(n=166) \text { vs Control }(n=192)\end{array}$ & TAGA & 0.038 & 0.019 & $2.79(0.99-7.88)$ & 0.054 & $1.73(0.48-6.21)^{\epsilon}$ & 0.40 \\
\hline
\end{tabular}

SNPs are sequentially located in each haplotype. CAD, coronary artery disease; CI, confidence interval; OR, odds ratio. ${ }^{*} \mathrm{OR}$ adjusted for age, gender, smoking, diabetes and hypertension. "OR adjusted for age, gender, smoking and hypertension. ${ }^{\epsilon}$ OR adjusted for age, gender, smoking and diabetes.

Table 4. Association of $G H R d 3$ copy number with coronary artery disease.

\begin{tabular}{lcccll}
\hline & \multicolumn{4}{c}{ GHRd3 $n(\%)$} & \\
\cline { 2 - 4 } Participants & 0-Copy & 1-Copy & 2-Copy & ${ }^{\text {a }} P_{\text {observed }}$ & $\mathrm{b}_{P_{\text {empirical }}}$ \\
\hline Controls & $93(35.8)$ & $105(48.6)$ & $33(61.1)$ & & \\
Cases & $167(64.2)$ & $111(51.4)$ & $21(38.9)$ & $<0.00001$ & $<0.00001$ \\
\hline a $P_{\text {observed }}$ unadjusted $P$ value calculated by Cochran-Armitage trend test. ${ }^{\mathrm{b}_{P_{\text {empirical }}}}$ \\
permutation $P$ value calculated using 10000 Monte Carlo simulations.
\end{tabular}

after adjusting for age, gender, diabetes, hypertension and smoking. There was significant association of the absence of GHRd3 allele with CAD as compared to subjects carrying 1 or 2 copies of the GHRd3 allele both before (OR 0.51 , 95\% CI: $0.36-0.73, P<0.00001)$ and after (OR 0.48, 95\% CI: $0.30-0.76, P=0.0014)$ correcting for confounders (table 5). The percentage PAR for the absence of a copy of GHRd3 allele was estimated to be $26.1 \%$ (95\% CI: $12.8 \%-$ $37.4 \%$ ). Chi-square analysis showed that there was no significant association between the copy number of GHRd3 allele and $G H 1$ gene promoter haplotypes.

\section{Phenotype-genotype analysis}

Multivariate analysis of plasma HDL-c levels with GHRd3 polymorphism showed that individuals with two copies of GHRd3 had significantly higher levels of HDL-c (46.99 $\mathrm{mg} / \mathrm{dL})$ followed by those with one copy $(41.47 \mathrm{mg} / \mathrm{dL})$ when compared to those with zero copy of the GHRd3 allele $(40.37 \mathrm{mg} / \mathrm{dL})(P=0.001)$. This difference remained significant even after adjustment for age, gender and smoking history. Subsequent to additional adjustment for statins, however, the association did not retain significance $(P=0.41)$ (table 6). There was no significant association of GHRd3 copy number variants with other plasma lipids, namely TC, TG, LDL-c levels and of $G H l$ variants with any of the plasma lipids.

\section{GH1 and stature}

There was no significant difference in the mean height between CAD patients and controls both in males $(166.04 \mathrm{~cm}$ and $166.45 \mathrm{~cm})$ and females $(154.26 \mathrm{~cm}$ and $152.2 \mathrm{~cm})$, respectively. However, CAD patients with history of stroke showed significantly lower mean height $(-0.243 \pm 0.106$, $160.60 \mathrm{~cm})$ as compared to CAD patients without stroke history $(0.077 \pm 0.047,163.32 \mathrm{~cm})(P=0.006)$ or the controls $(-0.027 \pm 0.051,162.44 \mathrm{~cm})(P=0.073)$ after correcting for age and gender (figure 2 ). The heterozygotes and homozygotes for the minor alleles of the haplotype tagging GH1 SNPs were combined for analysis for all four SNPs due to low frequency. The SNPs rs2005171 $(P=0.014)$, $\operatorname{rs} 11568828(P=0.030)$ and $\operatorname{rs} 2005172(P=0.023)$ showed significant association with height (figure 3, a-d). The GG genotype of rs2005171 was associated with decreasing height while the AA genotype of rs11568828 and the TT genotype of rs2005172 were associated with increasing height. Regression analysis showed that 10 of the 12 polymorphic SNPs were able to explain up to nearly $2.3 \%$ of variation in height in the overall data set. When analysis was performed based on gender, 11 of the 12 SNPs contributed significantly to $14.7 \%$ of variation in height in females ( $n=133, P=0.029$ ) and up to $3.5 \%$ of the variation in height in males $(n=343, P=0.276)$.

\section{Discussion}

Our present study on an Asian Indian cohort has revealed important leads that suggest a possible link between genetic variations in the receptor and ligand of the pituitary growth hormone with CVD and its comorbidities. Analysis of copy number variations of GHRd3 allele revealed significant association of genomic retention of exon 3 with CAD while 
Table 5. Assessment of different genetic models for GHRd3 copy number.

\begin{tabular}{|c|c|c|c|c|c|c|c|}
\hline \multirow[b]{2}{*}{ Model } & \multirow{2}{*}{$\begin{array}{c}\text { GHRd3 } \\
\text { copy } \\
\text { number }\end{array}$} & \multicolumn{3}{|c|}{${ }^{*}$ Unadjusted } & \multicolumn{3}{|c|}{${ }^{\dagger}$ Adjusted } \\
\hline & & ${ }^{\ddagger} \mathrm{OR}(95 \% \mathrm{CI})$ & $P$ value & AIC & OR $(95 \% \mathrm{CI})$ & $P$ value & ${ }^{\S} \mathrm{AIC}$ \\
\hline & 0 & 1.00 & & & 1.00 & & \\
\hline & 1 & $0.57(0.39-0.83)$ & & & $0.55(0.34-0.89)$ & & \\
\hline Codominant & 2 & $0.33(0.18-0.60)$ & $<0.00001$ & 712.1 & $0.29(0.13-0.65)$ & 0.0018 & 481.7 \\
\hline & 0 & 1.00 & & & 1.00 & & \\
\hline Dominant & $1-2$ & $0.5(0.36-0.73)$ & $<0.00001$ & 713.3 & $0.48(0.30-0.76)$ & 0.0014 & 482 \\
\hline Recessive & $\begin{array}{c}0-1 \\
2\end{array}$ & $\begin{array}{c}1.00 \\
0.43(0.24-0.77)\end{array}$ & 0.0038 & 719 & $\begin{array}{c}1.00 \\
0.39(0.18-0.82)\end{array}$ & 0.011 & 485.7 \\
\hline & $0-2$ & 1.00 & & & 1.00 & & \\
\hline Overdominant & 1 & $0.71(0.49-0.99)$ & 0.044 & 723.4 & $0.68(0.43-1.08)$ & 0.11 & 489.6 \\
\hline Logadditive & - & $0.57(0.44-0.75)$ & $<0.0001$ & 710.1 & $0.54(0.39-0.77)$ & $<0.00001$ & 479.7 \\
\hline
\end{tabular}

${ }^{*} P$ values were obtained from logistic regression modelling without any covariates. ${ }^{\dagger} P$ values were obtained from logistic regression modelling after adjustment for age, gender, diabetes, hypertension and smoking. ${ }^{\ddagger} \mathrm{OR}$, odds ratio, CI, confidence interval. ${ }^{\S} \mathrm{AIC}$, akaike information criterion.

Table 6. Multivariate analysis of GHRd3 copy number variation and plasma high density lipoprotein cholesterol levels.

\begin{tabular}{|c|c|c|c|c|c|c|}
\hline $\begin{array}{l}\text { GHRd3 } \\
\text { copy } \\
\text { number }\end{array}$ & $\begin{array}{c}\text { Unadjusted } \\
\text { mean } \pm \\
\text { SEM\# } \\
(\mathrm{mg} / \mathrm{di})\end{array}$ & $\begin{array}{c}P \\
\text { value }\end{array}$ & $\begin{array}{c}\text { Adjusted* }^{*} \\
\text { mean } \pm \\
\text { SEM\# } \\
(\mathrm{mg} / \mathrm{di})\end{array}$ & $\begin{array}{c}P \\
\text { value }\end{array}$ & $\begin{array}{c}\text { Adjusted }^{* *} \\
\text { mean } \pm \\
\text { SEM\# } \\
(\mathrm{mg} / \mathrm{di})\end{array}$ & $\begin{array}{c}P \\
\text { value }\end{array}$ \\
\hline 0 & $\begin{array}{c}3.7 \pm 0.02 \\
(40.37)\end{array}$ & & $\begin{array}{c}3.70 \pm 0.02 \\
\quad(40.24)\end{array}$ & & $\begin{array}{c}3.63 \pm 0.02 \\
(37.86)\end{array}$ & \\
\hline 1 & $\begin{array}{c}3.73 \pm 0.02 \\
\quad(41.47)\end{array}$ & $0.008^{\ddagger}$ & $\begin{array}{c}3.72 \pm 0.02 \\
\quad(41.10)\end{array}$ & $0.006^{\dagger}$ & $\begin{array}{c}3.56 \pm 0.03 \\
(35.21)\end{array}$ & $0.06^{\dagger}$ \\
\hline 2 & $\begin{array}{c}3.85 \pm 0.04 \\
(46.99)\end{array}$ & $0.001^{\dagger}$ & $\begin{array}{c}3.85 \pm 0.04 \\
(46.85)\end{array}$ & $0.001^{\ddagger}$ & $\begin{array}{c}3.69 \pm 0.06 \\
(39.96)\end{array}$ & $0.41^{\frac{1}{*}}$ \\
\hline
\end{tabular}

\# Log transformed mean \pm SD for HDL-c has been provided with the re-transformed means represented within brackets. SEM, standard error of mean. ${ }^{\dagger}$ Comparison of GHRd3, 1 copy versus 2 copy deletion. ${ }^{\ddagger}$ Comparison of $G H R d 3,0$ copy versus 2 copy deletion. *Adjusted for age, gender and smoking. ${ }^{* *}$ Adjusted for age, gender, smoking and statins.

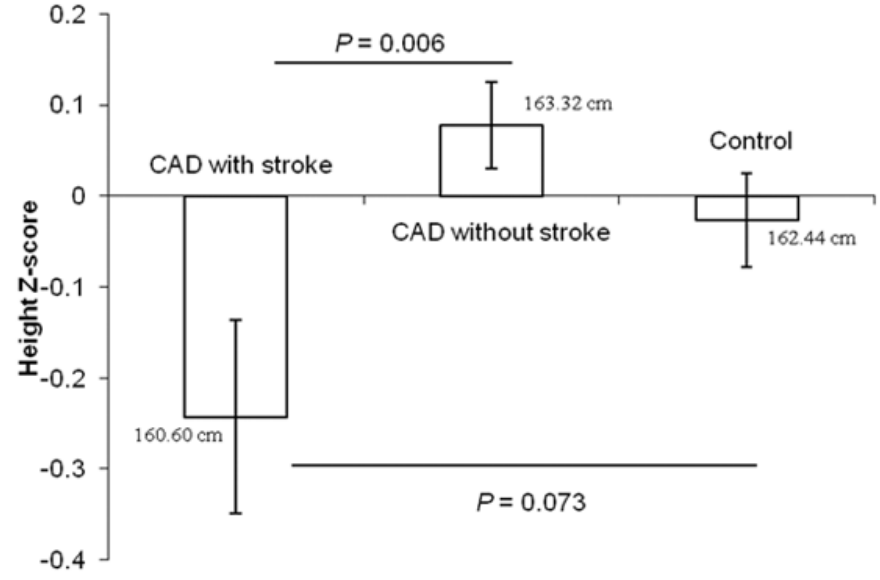

Figure 2. Analysis of variance of disease status with standardized height (height $\mathrm{Z}$-score); mean height indicated in $\mathrm{cm}$. 
A. rs2005171

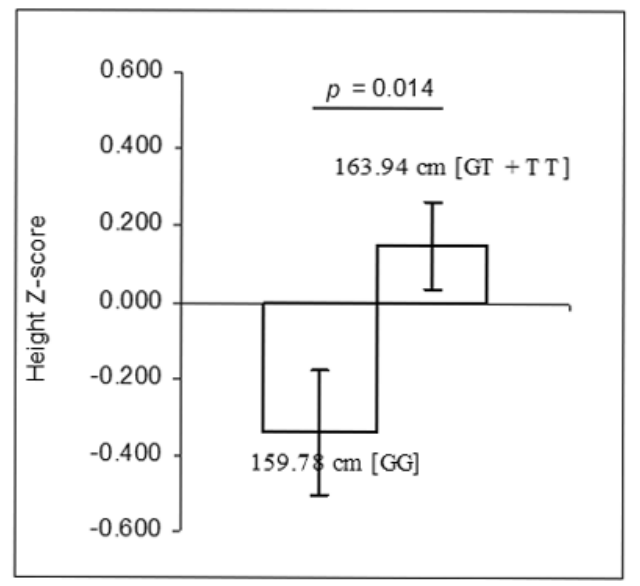

\section{C. rs2005172}

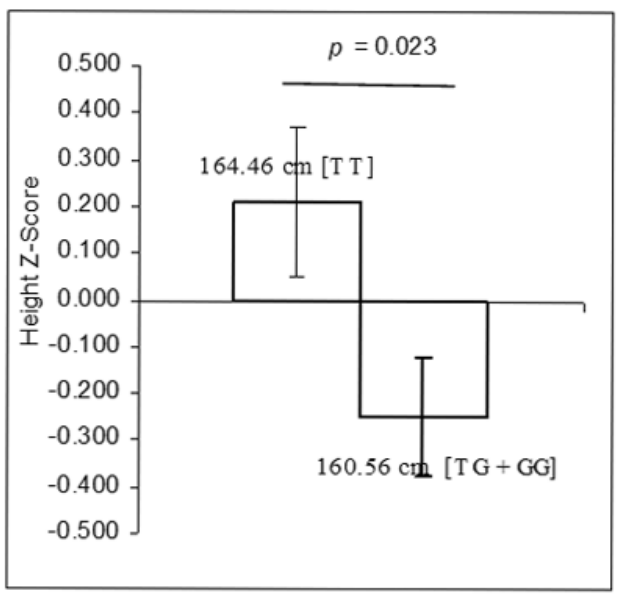

B. $\mathbf{r s 1 1 5 6 8 8 2 8}$

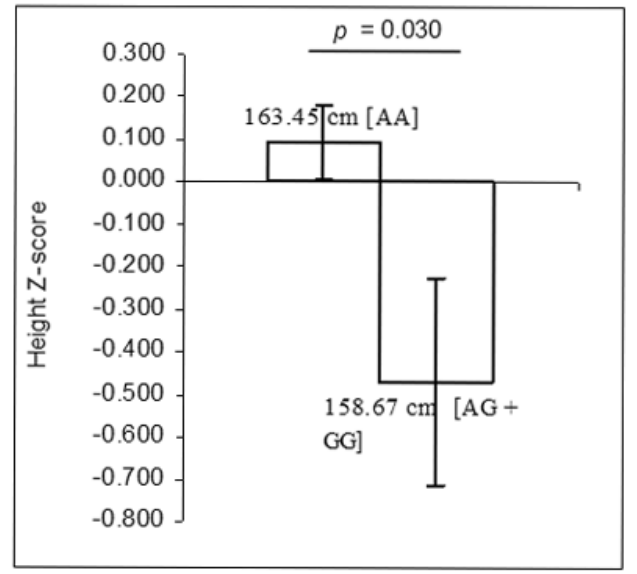

\section{D. rs6171}

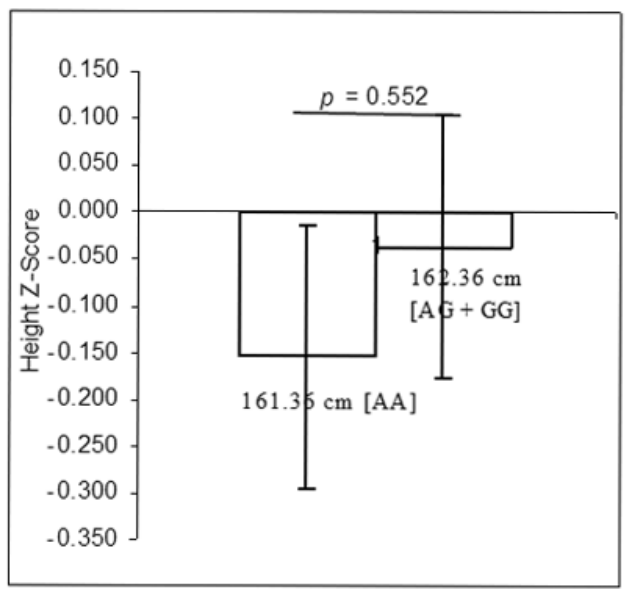

Figure 3. Univariate analysis of height Z-score with the four haplotype tagging SNPs; mean height indicated in $\mathrm{cm}$.

deletion of the same region was associated with higher plasma HDL-c levels. We identified 12 novel variants in the promoter region of $G H 1$ gene and a TAGA haplotype, constituted by functional SNPs that showed significant association with $\mathrm{CAD}$ alone or with $\mathrm{CAD}$ and diabetes when compared to clinically matched controls. Further, three of these promoter polymorphisms were significantly associated with stature.

The GHR gene encodes for a transmembrane receptor protein to which the growth hormone binds resulting in the activation of the signal transduction pathway leading to growth. There has been extensive discussions on the role of GHRd3 in modulating GH response in growth-retarded children with hormone deficiency (Jorge et al. 2006; Tauber et al. 2007) and in increased insulin secretion in healthy children and in adolescents during puberty (Sorensen et al. 2009). In the present study, the $G H R d 3$ allele exhibited protective effect against CAD accompanied by higher levels of HDL- c among subjects carrying the deletion allele after adjusting for age, gender and smoking. However, this association did not retain significance following adjustment for statins. This trend needs to be confirmed on a larger cohort. In a report on the response of short-term recombinant GH therapy in GH deficient adults, it has been shown that patients carrying at least one GHRd3 allele exhibited a significant increase in HDL-c levels as compared to those lacking a copy of the deletion (van der Klaauw et al. 2008), implicating the critical role of growth hormone in regulating lipoprotein metabolism. Further, the GHRd3 allele has been found to show a protective effect against development of type 2 diabetes in adult life (Strawbridge et al. 2007). A marginal association was shown between GHRd3 and hypertension in limited number female stroke patients (Horan et al. 2006). The strong association of full length exon 3 retention with CAD and higher plasma level of an atheroprotective biomarker like HDLc with GHRd3 in our cohort suggests that this variant 
can turn out to be a promising biomarker for CAD, worthy of further pursuit with respect to its diagnostic and therapeutic implications.

The $G H 1$ promoter region is highly polymorphic and regulates the inter-individual variation in the levels of GH expression in a complex and interdependent manner (Horan et al. 2003; Esteban et al. 2007). We identified 16 promoter SNPs of which four were invariant. The promoter SNPs exhibited moderate linkage disequilibrium. In addition, we discovered 12 novel variants that have not been hitherto observed in other populations. A recent report has suggested that the genetic architecture of Asian Indian population, a largely unexplored group to date, may possess discrete differences from that of the HapMap populations (Indian Genome Variation Consortium 2008).

We identified a risk haplotype, TAGA that was found to be significantly associated with CAD. The four haplotypetagging SNPs were confirmed to be the most informative markers in our cohort using multiple approaches. Three of these four SNPs were significantly associated with standardized height. Stepwise regression showed that the overall contribution of 11 of the 12 polymorphic promoter variants was $14.7 \%$ in females and only $3.5 \%$ in males. The above finding reiterates the complex nature of genetic regulation of stature (Mullis 2005) with minimal, additive contribution of individual SNPs with low penetrance. It is of interest to note that the TAGA haplotype includes two functional SNPs, the rs11568828 and rs2005172, which interact with the transcription factors namely, pituitary specific factor (Pit 1), the vitamin D responsive element (VDRE), the thyroid hormone (T3) and retinoic acid $(R A)$ (Suen et al. 1994; Cohen et al. 1996; Jimenez-Lara and Aranda 2000).

Epidemiological studies have shown a crucial link between adverse fetal environment and increased risk of metabolic disorders and CVD in adult life (Barker 1995). Administration of recombinant pituitary GH therapy in cases of GH deficiency has shown a positive effect on chronic cardiac failure (Le Corvoisier et al. 2007), ischemic cardiomyopathy (Genth-Zotz et al. 1999), reversal of early atherosclerotic changes (Pfeifer et al. 1999b) and lowering of hypertension, obesity (Vickers et al. 2002). An isolated report from south India has shown that individuals who were small at birth (weight $<2.5 \mathrm{~kg}$ at birth) or who were born to mothers with low body weight ( $<45 \mathrm{~kg}$ during pregnancy) showed greater predisposition to heart disease in adult life, possibly mediated by malnutrition (Stein et al. 1996). Significant association has been reported between $\mathrm{GHI}$ promoter haplotypes and risk of hypertension and stroke (Horan et al. 2006). It has been previously shown that in a West African population that elevated $\mathrm{GH} 1$ expression and GHR-mediated GH responsiveness may be attributed to an adaptive response against scarcity of food supply in this population (Millar et al. 2008). Our present findings reveal that the promoter haplotype of $\mathrm{GHI}$ gene might be associated with risk of CAD and diabetes in adult life. As our study was based on adult participants, lack of proper record of birth weight information in most of the patients and issues of recall bias were a hindrance for further investigations in this direction.

The finding of lower mean standardized height among CAD patients with stroke as compared to those without stroke and healthy controls in our cohort is noteworthy. An increased frequency of a $G H 1$ promoter haplotype was reported among hypertensive subjects and stroke patients as compared to controls. They also observed an inverse correlation between height and systolic blood pressure among carriers of the GHI risk haplotype (Horan et al. 2006). The frequency of cases carrying the risk haplotype, TAGA, in our study was very low, which precluded us from carrying out a detailed analysis.

Limitations in the present study are that the sample size is small. Also, the controls are on an average three years younger than the probands. As it is critical to have controls who are well matched to that of the cases, we will be testing our initial study findings on a larger cohort of 1000 CAD patients and 1000 controls who are matched for age, gender as well as ethnicity based on the mother tongue.

In conclusion, our preliminary study on a representative Asian Indian population at high risk of CVD reveals an interesting association between genetic variants in the $\mathrm{GH} 1$ promoter region and its receptor with $\mathrm{CAD}$ and stature. In light of the fact that Asian Indians have a small build, a unique fat distribution and a lower threshold for established risk factors that precipitate risk of CVD at an early age, the present findings provide an interesting insight on the novel genetic elements relating to growth and development in impacting CVD and its co-morbidities. Extended studies on a clinically well defined cohort, with characterization of the complete $\mathrm{GH} 1$ gene and its receptor, supported by functional validation may add yet another important dimension to the ongoing efforts to identify putative candidate genes that precipitate early predisposition to CVD in the Asian Indian population.

\section{Acknowledgements}

We are grateful for the encouragement given by the Trustees of TRI India and London towards the Indian Atherosclerosis Research Study and the Thrombosis Research Institute India. This work was supported by the Tata Social Welfare Trust, Garfield Weston Foundation, Department of Biotechnology and the Elizabeth and Emmanuel Kaye Foundation. We thank the doctors and management of Narayana Hrudayalaya, Bangalore, India, and the Asian Heart Institute and Research Center, Mumbai, India, for providing clinical assistance. We thank all the staff involved in cohort screening and enrolment, data entry and the TRI administrative team for their respective contributions and support provided for this study. We are obliged to the patients, their family members and controls for participating in our study.

\section{References}

Abramson J. H. 2004 WINPEPI (PEPI-for-Windows): computer programs for epidemiologists. Epidemiol. Perspect. Innov. 1, 6. 
Barker D. J. 1995 The fetal and infant origins of disease. Eur. J. Clin. Invest. 25, 457-463.

Barrett J. C., Fry B., Maller J. and Daly M. J. 2005 Haploview: analysis and visualization of LD and haplotype maps. Bioinformatics 21, 263-265.

Binder G., Trebar B., Baur F., Schweizer R. and Ranke M. B. 2008 Homozygosity of the d3-growth hormone receptor polymorphism is associated with a high total effect of GH on growth and a low BMI in girls with Tumer syndrome. Clin. Endocrinol. 68, 567-572.

Blum W. F., Machinis K., Shavrikova E. P., Keller A., Stobbe H., Pfaeffle R. W. and Amselem S. 2006 The growth response to growth hormone $(\mathrm{GH})$ treatment in children with isolated $\mathrm{GH}$ deficiency is independent of the presence of the exon 3-minus isoform of the GH receptor. J. Clin. Endocrinol. Metab. 91, 41714174.

Bondanelli M., Ambrosio M. R., Onofri A., Bergonzoni A., Lavezzi S., Zatelli M. C. et al. 2006 Predictive value of circulating insulin-like growth factor I levels in ischemic stroke outcome. J. Clin. Endocrinol. Metab. 91, 3928-3934.

Carrascosa A., Audi L., Esteban C., Fernandez-Cancio M., Andaluz P., Gussinye M. et al. 2008 Growth hormone (GH) dose, but not exon 3-deleted/full-length GH receptor polymorphism genotypes, influences growth response to two-year GH therapy in short small-for-gestational-age children. J. Clin. Endocrinol. Metab. 93, 147-153.

Cittadini A., Cuocolo A., Merola B., Fazio S., Sabatini D., Nicolai E. et al. 1994 Impaired cardiac performance in GH-deficient adults and its improvement after GH replacement. Am. J. Physiol. 267, E219-E225.

Climent V. E., Pico A., Sogorb F., Aznar S., Lip G. Y. and Marin F. 2006 Growth hormone therapy and the heart. Am. J. Cardiol. 97, 1097-1102.

Cohen L. E., Wondisford F. E. and Radovick S. 1996 Role of Pit-1 in the gene expression of growth hormone, prolactin, and thyrotropin. Endocrinol. Metab. Clin. North Am. 25, 523-540.

Esteban C., Audi L., Carrascosa A., Fernandez-Cancio M., PerezArroyo A., Ulied A. et al. 2007 Human growth hormone (GH1) gene polymorphism map in a normal-statured adult population. Clin. Endocrinol. 66, 258-268.

Friedewald W. T., Levy R. I. and Fredrickson D. S. 1972 Estimation of the concentration of low-density lipoprotein cholesterol in plasma, without use of the preparative ultracentrifuge. Clin. Chem. 18, 499-502.

Garcia-Aragon J., Lobie P. E., Muscat G. E., Gobius K. S., Norstedt G. and Waters M. J. 1992 Prenatal expression of the growth hormone $(\mathrm{GH})$ receptor/binding protein in the rat: a role for $\mathrm{GH}$ in embryonic and fetal development? Development 114, 869-876.

Genth-Zotz S., Zotz R., Geil S., Voigtlander T., Meyer J. and Darius H. 1999 Recombinant growth hormone therapy in patients with ischemic cardiomyopathy : effects on hemodynamics, left ventricular function, and cardiopulmonary exercise capacity. Circulation 99, 18-21.

Greenacre M. J. 1984 Theory and applications of correspondence analysis. Academic Press, London, UK.

Horan M., Millar D. S., Hedderich J., Lewis G., Newsway V., Mo N., Fryklund L. et al. 2003 Human growth hormone 1 (GH1) gene expression: complex haplotype-dependent influence of polymorphic variation in the proximal promoter and locus control region. Hum. Mutat. 21, 408-423.

Horan M., Newsway V., Yasmin N., Lewis M. D., Easter T. E., Rees D. A. et al. 2006 Genetic variation at the growth hormone (GH1) and growth hormone receptor (GHR) loci as a risk factor for hypertension and stroke. Hum. Genet. 119, 527-540.
Hubbard T. J., Aken B. L., Beal K., Ballester B., Caccamo M., Chen Y. 2007 Nucleic Acids Res. 35 (Database issue), D610-D617.

Indian Genome Variation Consortium 2008 Genetic landscape of the people of India: a canvas for disease gene exploration. $J$. Genet. 87, 3-18.

Jensen R. B., Vielwerth S., Larsen T., Greisen G., Leffers H. and Juul A. 2007 The presence of the d3-growth hormone receptor polymorphism is negatively associated with fetal growth but positively associated with postnatal growth in healthy subjects. $J$. Clin. Endocrinol. Metab. 92, 2758-2763.

Jimenez-Lara A. M. and Aranda A. 2000 Interaction of vitamin D and retinoid receptors on regulation of gene expression. Horm. Res. 54, 301-305.

Johnson R., McNutt P., MacMahon S. and Robson R. 1997 Use of the Friedwald formula to estimate LDL-cholesterol in patients with chronic renal failure on dialysis. Clin. Chem. 43, 2183 2184.

Jorge A. A., Marchisotti F. G., Montenegro L. R., Carvalho L. R., Mendonca B. B. and Arnhold I. J. 2006 Growth hormone (GH) pharmacogenetics: influence of GH receptor exon 3 retention or deletion on first-year growth response and final height in patients with severe GH deficiency. J. Clin. Endocrinol. Metab. 91, 10761080.

Ko J. M., Park J. Y. and Yoo H. W. 2009 Common exon 3 polymorphism of the GH receptor (GHR) gene and effect of GH therapy on growth in Korean children with idiopathic short stature (ISS). Clin. Endocrinol. 70, 82-87.

Kumar N. K. 2006 Bioethics activities in India. East Mediterr. Health J. 12 suppl 1, S56-S65.

Langenberg C., Hardy R., Breeze E., Kuh D. and Wadsworth M. E. 2005 Influence of short stature on the change in pulse pressure, systolic and diastolic blood pressure from age 36 to 53 years: an analysis using multilevel models. Int. J. Epidemiol. 34, 905-913.

Le Corvoisier P., Hittinger L., Chanson P., Montagne O., MacquinMavier I., Maison P. 2007 Cardiac effects of growth hormone treatment in chronic heart failure: A meta-analysis. J. Clin. Endocrinol. Metab. 92, 180-185.

McCarron P., Greenwood R., Ebrahim S., Elwood P. and Smith G. D. 2000 Adult height is inversely associated with ischaemic stroke. The Caerphilly and Speedwell collaborative studies. $J$. Epidemiol. Commun. Health 54, 239-240.

Millar D. S., Lewis M. D., Horan M., Newsway V., Rees D. A., Easter T. E. et al. 2008 Growth hormone (GH1) gene variation and the growth hormone receptor (GHR) exon 3 deletion polymorphism in a West-African population. Mol. Cell Endocrinol. 296, $18-25$.

Miller S. A., Dykes D. D. and Polesky H. F. 1988 A simple salting out procedure for extracting DNA from human nucleated cells. Nucleic Acids Res. 16, 1215.

Minczykowski A., Gryczynska M., Ziemnicka K., Czepczynski R., Sowinski J. and Wysocki H. 2005 The influence of growth hormone $(\mathrm{GH})$ therapy on cardiac performance in patients with childhood onset GH deficiency. Growth Horm. IGF Res. 15, 156164.

Mullis P. E. 2005 Genetic control of growth. Eur. J. Endocrinol. 152, 11-31.

Pfaffl M. W. A 2001 New mathematical model for relative quantification in real-time RT-PCR. Nucleic Acids Res. 29, 2002-2007.

Pfeifer M., Verhovec R. and Zizek B. 1999a Growth hormone (GH) and atherosclerosis: changes in morphology and function of major arteries during GH treatment. Growth Horm. IGF Res. 9, suppl. 25-30.

Pfeifer M., Verhovec R., Zizek B., Prezelj J., Poredos P. and Clayton R. N. 1999b Growth hormone (GH) treatment reverses 
early atherosclerotic changes in GH-deficient adults. J. Clin. Endocrinol. Metab. 84, 453-457.

Reed D. M., Resch J. A., Hayashi T., MacLean C. and Yano K. A. 1988 Prospective study of cerebral artery atherosclerosis. Stroke 19, 820-825.

Rodriguez S., Gaunt T. R. and Day I. N. 2007 Molecular genetics of human growth hormone, insulin-like growth factors and their pathways in common disease. Hum. Genet. 122, 1-21.

Sole X., Guino E., Valls J., Iniesta R. and Moreno V. 2006 SNPStats: a web tool for the analysis of association studies. Bioinformatics 22, 1928-1929.

Song Y. M., Smith G. D. and Sung J. 2003 Adult height and causespecific mortality: a large prospective study of South Korean men. Am. J. Epidemiol. 158, 479-485.

Sorensen K., Aksglaede L., Munch-Andersen T., AachmannAndersen N. J., Leffers H., Helge J. W. et al. 2009 Impact of the growth hormone receptor exon 3 deletion gene polymorphism on glucose metabolism, lipids, and insulin-like growth factor-I levels during puberty. J. Clin. Endocrinol. Metab. 94, 2966-2969.

Stein C. E., Fall C. H., Kumaran K., Osmond C., Cox V. and Barker D. J. 1996 Fetal growth and coronary heart disease in south India. Lancet 348, 1269-1273.

Strawbridge R. J., Karvestedt L., Li C., Efendic S., Ostenson C. G.,
Gu H. F. and Brismar K. 2007 GHR exon 3 polymorphism: association with type 2 diabetes mellitus and metabolic disorder. Growth Horm. IGF Res. 17, 392-398.

Suen C. S., Yen P. M. and Chin W. W. 1994 In vitro transcriptional studies of the roles of the thyroid hormone (T3) response elements and minimal promoters in T3-stimulated gene transcription. J. Biol. Chem. 269, 1314-1322.

Tauber M., Ester W., Auriol F., Molinas C., Fauvel J., Caliebe J. et al. $2007 \mathrm{GH}$ responsiveness in a large multinational cohort of SGA children with short stature (NESTEGG) is related to the exon 3 GHR polymorphism. Clin. Endocrinol. 67, 457-461.

van der Klaauw A. A., van der Straaten T., Baak-Pablo R., Biermasz N. R., Guchelaar H. J., Pereira A. M. et al. 2008 Influence of the $\mathrm{d} 3$-growth hormone $(\mathrm{GH})$ receptor isoform on short-term and long-term treatment response to $\mathrm{GH}$ replacement in GH-deficient adults. J. Clin. Endocrinol. Metab. 93, 2828-2834.

Vickers M. H., Ikenasio B. A. and Breier B. H. 2002 Adult growth hormone treatment reduces hypertension and obesity induced by an adverse prenatal environment. J. Endocrinol. 175, 615-623.

World Medical Association declaration of Helsinki 1997 Recommendations guiding physicians in biomedical research involving human subjects. JAMA 277, 925-926. 